\title{
Qualidade de vida e fontes de pressão no trabalho do consultor organizacional em Belo Horizonte
}

\author{
.Lúcio Flávio Renault de Moraes, $\mathrm{PhD}^{1}$ \\ Carlos Roberto Sícoli, ${ }^{2}$.
}

\begin{abstract}
Resumo
O achatamento das estruturas organizacionais, os chamados "downsizing", as reengenharias, a terceirização de atividades não vinculadas ao negócio principal da empresa, levaram ao desemprego milhares de pessoas no Brasil, bem como abriram novas oportunidades de negócios, entre eles o trabalho de consultorias. As consultorias e os consultores é que vão contribuir para que as empresas descubram novas alternativas de trabalho, explorem novas oportunidades, desenvolvam novos talentos ou mesmo vão facilitar a transição destas de um estado atual para outro estado desejado e mais propício às suas necessidades, interesses e objetivos.

O presente estudo teve o objetivo de retratar a realidade da qualidade de vida no trabalho destes profissionais que atuam como consultores de empresas e conhecer as fontes de pressão no trabalho, presentes em seu dia-a-dia. Buscou levantar as condições que estão interferindo em seu trabalho e influenciando seu comportamento dentro e fora dele.
\end{abstract}

Palavras-chave: consultores, consultoria, pressão no trabalho, qualidade de vida. Abstract

If recent processes of organizational restructuring, such as downsizing, re-engineering and not- related-to-core-business-work outsourcing have, on the one hand, produced massive unemployment in Brazil, on the other hand, they have created opportunities for new businesses, among which, one can mention consulting services. This paper argues that consulting services and consultant businessmen would in fact contribute to new work opportunities, job creation, talent deployment or company transition to new thresholds of development which are much more adequate to their needs, interests and goals. This study aimed at portraying the life quality aspects as well as work pressures in daily routines of these consulting professionals. The research sought to analyze conditions which interfere with the work of such professionals both inside and outside their working environment.

Key Words: Consultants, consulting, work pressure, life quality.

\section{INTRODUÇÃO}

$\mathrm{O}$ ritmo acelerado das mudanças atuais parece marcar um cenário no qual as empresas e as pessoas que as constituem têm que buscar, a todo custo, adaptar-se, adotar uma postura proativa ou reagir rapidamente ao ambiente de mudanças tecnológicas, políticas, econômicas, sociais e culturais que estão ocorrendo, forçando-as

\footnotetext{
${ }_{1}^{1}$ Doutor, Professor do MPA, Faculdades Integradas da Fundação Pedro Leopoldo.

${ }^{2}$ Mestre em Administração.
} 
a reverem estruturas, políticas, filosofias de trabalho e de relacionamento empresarial e pessoal.

Segundo dados do Cadastro Geral de Empregados e Desempregados - CAGED do Ministério do Trabalho e Emprego - MTE - no setor formal do mercado de trabalho, onde estão os trabalhadores protegidos por contratos de trabalho e empregados públicos, foram eliminados cerca de 2,56 milhões de empregos entre janeiro de 1990 e dezembro de 1997. Ao mesmo tempo, houve crescimento do chamado trabalho informal e autônomo, inclusive com profissionais de nível superior que passaram a engrossar as estatísticas referentes ao desemprego no País. O volume e a rapidez do declínio no número de postos de trabalho originam-se do processo de abertura comercial que substituiu o antigo modelo de industrialização protegida, característica do desenvolvimento brasileiro até o final dos anos 80 (BRASIL, 1999).

Segundo Wood (1995), quando o ritmo das mudanças era mais lento, até meados do século passado, predominava uma postura administrativa com tendência à continuidade, em que os administradores trabalhavam vislumbrando um futuro semelhante ao passado, traçando objetivos e metas com base em extrapolações de experiências anteriores, com pequenos ajustes às situações vividas, no momento de seus planejamentos. As mudanças atuais ocorrem em ritmo mais intenso, são descontínuas e imprevisíveis em geral. Pessoas e empresas buscam adequar-se rapidamente às mudanças nos ambientes externo e interno, procurando ajustar-se com resultados efetivos aos seus interesses, objetivos e necessidades presentes.

Paradoxalmente, essa situação de busca de recursos externos e novas competências acabam abrindo espaço para a contratação de outros profissionais, especialistas de áreas fora da competência principal das empresas, que vão ajudá-las a explorar novas oportunidades, propor novas alternativas de ação ou mesmo facilitar a transição de um estado atual não satisfatório para um estado desejado mais propício às suas necessidades, interesses e objetivos.

Nesse contexto, entram em cena os consultores organizacionais autônomos ou as empresas de consultoria, com suas equipes de consultores, para ajudar dirigentes e empresas na empreitada de adequação a uma nova realidade.

Os empresários contratam os consultores organizacionais geralmente para projetos de curta duração, e/ou porque precisam da visão de um especialista, e/ou porque necessitam de uma pessoa para mediar uma situação de forma independente, e/ou para projetos visando readaptações ou reestruturações, redução de custo, aumento de produtividade, lucratividade ou rentabilidade, e/ou para confirmar uma posição já estabelecida por alguém da direção, e/ou por outros possíveis motivos a serem apresentados no decorrer deste trabalho. Ao consultor cabe estabelecer uma relação de parceria com seu cliente, contribuir para o sucesso deste e seu próprio, conciliar seus valores éticos, filosofia de trabalho, idéias e ideais com os da empresa. Além disso, os consultores devem equilibrar suas ambições, necessidades de sucesso e sobrevivência, transferir seu expertise, seu know-how de competências, experiências e talento, dedicando-se ao trabalho de consultor com maior engajamento, dedicação e vocação para a profissão (BELLMAN,1993).

Para Veiga (2000), os sucessivos processos de downsizing, reestruturações e reengenharias organizacionais que marcaram a década de 1990 exigiram que as pessoas cada vez trabalhassem mais e, por consequiência, tenham dedicado cada vez menos tempo a si mesmas, ao lazer e à família, afetando a chamada Qualidade de Vida.

A insegurança gerada pelas reduções nas estruturas organizacionais ou pela sensação das pessoas de estarem desatualizadas profissionalmente, a insegurança de ter ou não trabalho e a inconstância dos rendimentos do trabalhador autônomo são algumas 
questões também abordadas no estudo de Kilimnik e Rodrigues (2000), que mostram a busca das pessoas em alcançar, como autônomos ou profissionais liberais, uma melhor qualidade de vida no trabalho.

\subsection{Delimitação do estudo}

O foco deste trabalho se situou no conteúdo e no contexto de trabalho do profissional consultor, que se dedica a essa profissão, seja por vocação, por decisão própria, por falta de opção de emprego remunerado ou por facilidade fornecida por exempregador para sua atuação.

Na busca de retratar uma realidade vivida pelos consultores organizacionais que atuam com aspectos relacionados à gestão de pessoas em empresas de vários tipos e portes, certamente não foram englobados todos os aspectos envolvidos na relação do consultor com seus clientes/empresas. Aspectos como a tecnologia empregada pela empresa, o processo decisório, a propensão às mudanças pelas empresas ou a cultura de cada uma, embora possam afetar a atuação do consultor, não foram objetos desta pesquisa.

\subsection{Relevância do estudo}

Embora exista uma significativa quantidade de estudos e abordagens sobre Qualidade de Vida no Trabalho - QVT - desconhecemos qualquer estudo abordando a qualidade de vida e fontes de pressão no trabalho daqueles que se dedicam à consultoria externa nas organizações, com exceção do estudo recentemente divulgado por Kilimnik e Castilho (2002) e Kilimnik e Rodrigues (2000) que investigaram o trabalho de alguns profissionais ligados à área de recursos humanos que passaram a atuar como consultores autônomos.

Para Bellman (1993), existem consultores organizacionais que atuam como tal por opção própria e outros que ficaram desempregados e trabalham para sobreviver, podendo sujeitar-se a qualquer condição imposta pelas empresas. Pessoas se lançam no mercado como consultores organizacionais, conhecendo muito pouco sobre a realidade do trabalho que os espera, quais as verdadeiras condições de trabalho, quais os riscos envolvidos nessa profissão, quais as pressões que poderão sofrer no ambiente profissional, nas empresas e na concorrência com outros profissionais e na própria vida familiar.

Portanto, o presente estudo justificou-se por pretender preencher essa lacuna no estudo da Qualidade de Vida no Trabalho de profissionais que atuam como consultores organizacionais e conhecer as fontes de pressão envolvidas nas atividades inerentes a essa profissão. Conseqüentemente, poderá ser útil no fornecimento de subsídios àqueles que pretendem ingressar na profissão, podendo vir a facilitar a adequação desses à realidade da vida profissional do consultor organizacional bem como às empresas que contratam esses profissionais.

\section{REFERENCIAL TEÓRICO}

\subsection{Qualidade de vida no trabalho - QVT}

A década de 1950 marca o início de estudos sobre Qualidade de Vida no Trabalho, como uma abordagem que focava o comportamento humano na organização, mais genericamente com a satisfação do trabalhador em seu trabalho e na realização das 
tarefas inerentes ao seu cargo. Desde os primórdios da administração se pesquisa o que faz o homem trabalhar melhor e mais satisfeito, sendo desenvolvidas diversas abordagens como as de Taylor e Fayol, no início do século passado, passando pela Teoria das Relações Humanas, Neoclássica, Comportamental ou pela Teoria Contingencial .

Estudos realizados por Eric Trist e colaboradores, no início da década de 1950, em uma mina de carvão, onde haviam sido introduzidas novas formas de trabalho e mecanização de atividades, constataram que as novas formas de realização das atividades inerentes a cada profissão, decorrentes dos processos de mecanização, estavam sendo rejeitadas e substituídas por métodos anteriores de produção (TRIST, 1981).

A expressão Qualidade de Vida tem sido usada com crescente freqüência para descrever certos valores ambientais e humanos, negligenciados pelas sociedades industriais em favor do avanço tecnológico, da produtividade e do crescimento econômico (WALTON, 1973).

Para Berger (1983), o trabalho humano é a atividade fundamental que vai possibilitar a modificação do mundo e as transformações da existência humana. Todavia, a divisão do trabalho favoreceu a perda de identidade do trabalhador na realização de seu trabalho, impulsionando-o a concentrar esforços na busca de fontes de auto-identificação e de significado pessoal em outras atividades.

Gorz (1980) ressalta que os conhecimentos, a inteligência e a vontade do trabalhador foram retirados pela divisão do trabalho e colocados à disposição do capital, representado pelas máquinas, tecnologia e organização do trabalho.

Os estudos sobre motivação desenvolvidos por A. Maslow (1954) constituíramse em marco importante para o estudo da Qualidade de Vida no Trabalho. Maslow (1954) afirmava que o comportamento de uma pessoa era motivado pela necessidade de satisfação de uma hierarquia de necessidades, iniciando-se pelas necessidades fisiológicas básicas ou necessidades de sobrevivência, as necessidades de segurança, necessidades sociais ou de pertencer a grupos sociais, necessidades de auto-estima ou de reconhecimento de si mesmo e de reconhecimento pelas pessoas ou organizações e, finalmente, as necessidades de realização pessoal.

Para Herzberg (1968), a motivação estaria relacionada a fatores que produzem: 1. satisfação, relacionada ao conteúdo da tarefa; 2 . insatisfação, relacionada ao ambiente de trabalho. Para o autor, as pessoas demonstram dois tipos de necessidades relacionados aos fatores de insatisfação e de satisfação, chamados de fatores higiênicos e fatores de motivação ou de satisfação. As políticas de administração, a remuneração paga e a segurança no trabalho seriam alguns dos fatores cuja ausência ou inadequação causariam desmotivação nas pessoas, embora sua presença não proporcionasse motivação, mas tão-somente evitasse a desmotivação.

Os fatores de motivação, citados pelo mesmo autor, estariam relacionados à satisfação das pessoas no trabalho, relacionadas ao conteúdo do trabalho e representado pelo reconhecimento em relação ao trabalho realizado, a responsabilidade e $\mathrm{o}$ reconhecimento pela responsabilidade assumida nos cargos, o desenvolvimento e o progresso profissional.

Tanto Maslow (1954) quanto Herzberg (1968) baseiam-se na premissa de que há sempre uma melhor forma de despertar a motivação nas pessoas, seja por meio da satisfação de uma necessidade premente, seja via enriquecimento das tarefas.

Para Walton (1973), Qualidade de Vida no Trabalho está relacionada a valores ambientais e humanos que as organizações têm deixado de lado em sua busca de avanço tecnológico, de produtividade e de crescimento econômico. Uma organização deveria 
oferecer aos seus membros, na busca de melhoria de qualidade de vida, as seguintes variáveis:

- compensação justa e adequada: com justiça na compensação, participação na produtividade, proporcionalidade da remuneração à complexidade dos trabalhos realizados;

- condições de trabalho adequadas: com jornada de trabalho razoável, ambiente físico seguro e saudável e sem insalubridade;

- possibilidade de uso e desenvolvimento de suas capacidades: com autonomia, uso de múltiplas habilidades, informações sobre o processo total de trabalho, realização de tarefas significativas, planejamento e implementação de atividades;

- oportunidade de crescimento e segurança: possibilidade de carreira e crescimento pessoal, de melhoria na remuneração e com segurança no emprego;

- integração social na organização: com igualdade de oportunidades, ausência de preconceitos, relacionamento interpessoal aberto e senso comunitário;

- constitucionalismo: com normas e procedimentos que enfatizem o respeito às leis e direitos trabalhistas, liberdade de expressão, privacidade pessoal e imparcialidade;

- trabalho e espaço total de vida: com estabilidade de horários, de local de trabalho, com tempo para dedicar-se à família e ao lazer e a outras atividades comunitárias ou não;

- relevância social da vida no trabalho: com imagem e administração da empresa que valorize a auto-estima e produtividade do trabalhador, que exerça a responsabilidade social e dos produtos da empresa.

Moraes (1994), em estudo sobre a qualidade de vida de algumas profissões de risco, cita a importância que a teoria de Frederick Herzberg trouxe para os estudos da Qualidade de Vida no Trabalho e faz um paralelo entre a tríade "fatores-atitudesefeitos" desenvolvida por Frederick Herzberg, em 1968, e o modelo desenvolvido por Hackman e Oldham (1975) para estudo da QVT que está representado pela tríade dimensões básicas da tarefa - estados psicológicos críticos - respostas afetivas ao trabalho.

Hackman e Oldham (1975) desenvolveram seus estudos numa abordagem que, embora estivesse focada em trabalhadores com vínculo empregatício, apresentaram muitos aspectos que se aplicam àqueles que se dedicam à consultoria, especialmente àqueles empregados em grandes empresas de consultoria, que são assalariados como qualquer outro profissional empregado em empresas.

Esses autores, cujos fundamentos serviram de base para este trabalho, afirmam que os trabalhadores estarão motivados, satisfeitos, desempenharão suas tarefas com qualidade, produtividade e assiduidade no trabalho, quando três estados psicológicos estiverem presentes nos indivíduos:

- Significação Percebida - SP - grau em que o indivíduo percebe a importância, valor e significância de seu trabalho;

- Responsabilidade Percebida - RP - grau de responsabilidade que o indivíduo experimenta em relação aos resultados de seu trabalho;

- Conhecimento dos Resultados de Trabalho - CRT - grau de entendimento do indivíduo quanto à efetividade de seu trabalho.

Por sua vez, estes estados seriam criados por sete dimensões básicas oriundas das tarefas executadas pelos indivíduos: 
- Variedade de Habilidade - VH - grau em que a tarefa requer, para sua execução, o envolvimento e o uso de várias habilidades e talentos de um mesmo indivíduo;

- Identidade da Tarefa - IT - grau em que uma tarefa é realizada de maneira completa (do início ao fim) e é identificável com resultados visíveis;

- Significação da Tarefa - ST - grau em que o trabalho do indivíduo impacta o trabalho de outros, tanto da organização quanto fora dela;

- Autonomia - AU - grau de liberdade e independência do indivíduo para estabelecer os procedimentos de seu trabalho;

- Feedback Extrínseco - FE - grau em que o desempenho do indivíduo é avaliado por meio de informações recebidas dos superiores, colegas ou clientes;

- Feedback Intrínseco - FI - grau em que a tarefa requer do indivíduo o trato direto com outras pessoas e clientes internos ou externos.

O modelo desenvolvido por Hackman e Oldham (1975), para avaliação dos fatores acima citados, foram completados com outros dois grupos de variáveis: Resultados Pessoais e de Trabalho e Satisfações Contextuais.

No primeiro grupo, busca-se identificar as reações afetivas e sentimentos que uma pessoa expressa ao realizar seu trabalho:

- Satisfação Geral com o Trabalho - SGT - medida geral do nível em que a pessoa está satisfeita em seu trabalho;

- Motivação Interna para o Trabalho - MIT - grau de automotivação que a pessoa sente ao realizar seu trabalho;

- Produção de Trabalho de alta Qualidade - PTQ - grau em que o trabalho produzido por uma pessoa é considerado de qualidade superior;

- Absenteísmo e Baixa Rotatividade - ABR - nível de faltas ao trabalho e rotatividade de pessoas.

No segundo grupo, chamado satisfações contextuais, incluem-se variáveis que buscam investigar o bem-estar das pessoas em relação a:

- Satisfação com a Possibilidade de Crescimento - SPC - possibilidade de se desenvolver profissional e pessoalmente;

- Segurança no Trabalho - SS - segurança com a empresa e com o trabalho;

- Compensação - SC - compensação satisfatória em relação ao trabalho executado e ao mercado externo;

- Ambiente Social - SAS - ambiente de inter-relacionamento social satisfatório na empresa;

- Supervisão - SSU - supervisão satisfatória recebida com orientações adequadas.

\subsection{Fontes de pressão no trabalho}

Segundo Evans (1996), uma tendência social muito marcante é a busca da autonomia. As pessoas querem se sentir independentes, autônomas; querem ter o controle de suas vidas, distanciando-se do poder impessoal, que representa autoridade. Por outro lado, as organizações buscam não apenas profissionais engajados, envolvidos numa relação de prazer com suas funções, mas também devem procurar fornecer um ambiente de trabalho baseado em valores básicos e simples da vida como a autonomia, a confiança e a clareza de objetivos. 
O papel do trabalhador na sociedade mudou muito rapidamente, e o quadro competitivo indica que as empresas tendem a dispor de um número muito menor de pessoas em seus quadros. Em consequiência, as pessoas terão que desenvolver cada vez mais funções e se aperfeiçoar cada vez mais.

Cooper, Sloan e Williams (1988) abordaram a questão das exigências de preparo constante dos trabalhadores para conseguirem acompanhar as constantes mudanças tecnológicas que ocorrem cada vez mais rapidamente. Segundo estes autores, o estresse decorre de características negativas no ambiente percebidas pelo indivíduo, as quais são capazes de lhe trazerem conseqüências físicas ou mentais indesejáveis. Essas percepções são resultantes da incapacidade do indivíduo de combater por si só as fontes causadoras de estresse.

Para Albretch (1988), a produtividade é resultante da capacidade, interesse e competência do trabalhador, que se sente produtivo à medida que recebe a remuneração de acordo com o que faz e segundo a complexidade das tarefas exercidas. Se o trabalhador é exigido dentro de limites pessoais estabelecidos, ele vai reagir de acordo com a pressão recebida e desafios percebidos. $\mathrm{O}$ autor considera ainda que, para o equilíbrio entre o indivíduo e a organização, é necessário que as condições de produtividade, citadas no parágrafo anterior, sejam satisfeitas. Esse equilíbrio é considerado como uma zona de conforto que permite que o indivíduo funcione bem e satisfaça suas necessidades. As condições físicas do trabalho, o volume e variedade das tarefas, o nível de controle exercido e o status e desafios representados pelo trabalho executado desempenham um papel importante nesta zona de conforto. Esses fatores são fontes de pressão que geram os estresses ocupacionais, que é entendido por este autor como consequiência da falta ou do excesso desses fatores, que podem comprometer o desempenho e provocar efeitos colaterais indesejáveis no indivíduo.

Já Arroba e James (1988) consideram as fontes de pressão ocupacional como sendo o estresse manifestado quando as pessoas estão trabalhando. Todavia, apontam também que nem sempre as fontes de pressão são oriundas diretamente do trabalho realizado ou decorrente de acontecimentos no trabalho. Fatores relacionados com as expectativas econômico-financeiras do indivíduo, com questões políticas ou com questões relacionadas a aspectos sociais ou culturais também devem ser consideradas como fontes de pressão sobre o indivíduo.

Para Albrecht (1988), num ambiente de trabalho, se não houver certo grau de pressão, não haverá estímulo dos indivíduos para o trabalho ou para enfrentar desafios, superar obstáculos e produzir mais. Isso seria até benéfico, contribuindo para que as pessoas se tornem saudáveis, produtivas e satisfeitas com a organização em que atuam, exigindo cada vez mais esforço para alcançar os resultados esperados.

A contrapartida oferecida pelas empresas pelo esforço exigido daqueles que atuam na organização nem sempre é devidamente proporcional. Oliveira (1988) destaca que as empresas exigem cada vez mais dos empregados, em termos de utilização de todo o seu capital intelectual e total comprometimento com o trabalho. Mas não se comprometem com os indivíduos, exigindo que eles exercitem sua empregabilidade se quiserem manter seus empregos. Tais exigências podem vir a constituir-se fontes de pressão causadoras de estresse nos indivíduos.

O modelo teórico de pressão no trabalho que foi utilizado foi desenvolvido por Cooper, Sloan e Williams (1988) e levou à criação de instrumento denominado Ocupational Stress Indicator - OSI - tendo sido traduzido e adaptado por Moraes, Swan \& Cooper (1993), com objetivo de levantar as fontes de pressão no trabalho que atuam como agentes estressores nas organizações. 
Para Cooper, Sloan e Williams (1988), os agentes estressores são comuns a todo trabalho ou ocupação, variando os tipos de agentes e a potência de sua manifestação de acordo com as características da organização em que o indivíduo atua e com a personalidade da própria pessoa.

Seis categorias foram estabelecidas pelos autores para determinar as fontes de pressão potencialmente geradoras de estresse, apresentadas na figura 1.

\begin{tabular}{|c|l|}
\hline CATEGORIAS DE FATORES & \multicolumn{1}{|c|}{ FONTES DE PRESSÃO } \\
\hline Fatores Intrínsecos ao trabalho & $\begin{array}{l}\text { Volume de trabalho, surgimento de novas } \\
\text { tecnologias, natureza e conteúdo das tarefas } \\
\text { realizadas ou exigidas, ritmo de trabalho. }\end{array}$ \\
\hline Relacionados ao Papel Gerencial & $\begin{array}{l}\text { Nível de supervisão e controle sobre o } \\
\text { trabalho. }\end{array}$ \\
\hline Fatores de Inter-relacionamento & $\begin{array}{l}\text { Apoio, disponibilidade para o outro, } \\
\text { atitudes de isolamento, conflitos de } \\
\text { personalidade. }\end{array}$ \\
\hline $\begin{array}{c}\text { Relacionados ao Desenvolvimento da } \\
\text { Carreira ou Realização }\end{array}$ & $\begin{array}{l}\text { Sistema de compensação, oportunidades de } \\
\text { desenvolvimento treinamento, } \\
\text { reconhecimento e valorização do } \\
\text { desempenho, perspectivas de melhoria ou } \\
\text { promoção, segurança. }\end{array}$ \\
\hline Orgacionados à Estrutura e Clima & $\begin{array}{l}\text { Políticas valores empresariais, nível de } \\
\text { comunicação, recursos financeiros, clima } \\
\text { de trabalho, características estruturais. }\end{array}$ \\
\hline Interface Casa/ Trabalho & $\begin{array}{l}\text { Ocorrências externas ao trabalho, apoio } \\
\text { familiar, afastamento ou aposentadoria, } \\
\text { instabilidade ou insegurança familiar, } \\
\text { conciliação ou conflito entre a carreira e a } \\
\text { vida familiar. }\end{array}$ \\
\hline
\end{tabular}

Figura 1 - Quadro mostrando fatores e fontes de pressão no trabalho

Fonte - Occupational Stress Indicator - OSI - COOPER et al (1988)

A decisão de utilizarmos o modelo teórico de Cooper, Sloan e Williams (1988), que permitiu aos autores a criação do OSI baseia-se em Moraes (1994), que considera ser o instrumento uma opção segura e viável de pesquisa, aliando estrategicamente praticidade e eficácia, já que se baseia em um modelo teórico validado internacionalmente, tendo se revestido de um caráter prático ao resgatar mais de 25 anos de pesquisas empíricas na área.

O levantamento das fontes de pressão permitiu conhecer melhor os aspectos que podem estar interferindo na qualidade de vida do profissional que se dedica ao trabalho de consultor organizacional, cujos aspectos teóricos serão expostos a seguir.

\subsection{O consultor organizacional}

A palavra consultor vem do latim - consultare - que significa dar ou receber conselhos, aconselhar e também ser aconselhado. 
Segundo Bretas Pereira (1999), o ser humano sempre procurou a ajuda de outro quando se sentiu em dificuldades, aconselhando-se com quem supunha deter mais conhecimento ou fosse capaz de ajudá-lo a resolver seus problemas. Ter conhecimento e capacidade de ajudar alguém a tomar decisões importantes constituiu-se fonte inesgotável de poder e prestígio.

Schein (1972), um dos primeiros autores conhecidos a publicar um livro sobre o tema, destaca as dificuldades que podem ser enfrentadas pelo consultor no processo de consultoria. Para o autor, é muito importante ajudar o dirigente da empresa a definir qual é o problema para, somente a partir daí, decidir a forma como a empresa pode ser ajudada. Os dirigentes das empresas sentem, frequientemente, que nem tudo vai bem ou que as coisas poderiam estar melhores não sabendo, porém, como traduzir essas vagas sensações para ações concretas.

Ao definir a consultoria de procedimentos, Schein (1972) destaca que esta não pressupõe que o administrador saiba o que está errado, o que é necessário ou o que o consultor deve fazer. $O$ que se espera para que o processo comece de maneira construtiva é a intenção do dirigente de melhorar a situação vigente. $\mathrm{O}$ administrador deve agir em conjunto com o consultor no diagnóstico da situação, mesmo porque, raramente, o consultor conhece suficientemente a empresa para saber, com segurança, qual o melhor caminho a seguir. O papel do consultor, para esse autor, consiste em ensinar técnicas de diagnose e de resolução de problemas, mas ele próprio não deve se envolver na solução do problema real. Para este autor os administradores não sabem o que está errado e necessitam de uma ajuda especial para diagnosticarem seus problemas e desconhecem que tipo de ajuda os consultores podem lhes prestar, precisando de ajuda para isto. Os administradores têm a intenção construtiva de melhorar as coisas, mas necessitam de ajuda para identificar o que melhorar e como melhorar. Como o consultor não conhece suficientemente a cultura da organização, ele deve trabalhar em conjunto com os membros da organização, sendo seu papel oferecer novas alternativas para serem consideradas pelo cliente. A tomada de decisões deve ser do cliente, e o consultor funciona apenas como um elemento de apoio, desenvolvendo diagnósticos e estabelecendo um relacionamento que possa, efetivamente, ajudar seus clientes.

Posição diferente é adotada por Greenbraum (1991), ao afirmar que o consultor pode e deve, muitas vezes, assumir o papel de consultor-líder do processo de transformação da empresa, podendo vir a enfrentar grandes resistências dentro das organizações. Para esse autor, o consultor deve, não apenas apresentar resultados, mas também provar ao cliente que vale a pena manter essa relação, porque oferece um serviço que é benéfico ao crescimento da empresa. Manter as relações de prestação de serviço é, para esse autor, uma das partes mais difíceis do trabalho de um consultor.

Block (1991) considera que a meta ou produto final em qualquer atividade de consultoria é chamado de intervenção. $\mathrm{O}$ termo intervenção descreve qualquer ação que o consultor adota em relação a um sistema do qual não faz parte.

$\mathrm{O}$ autor ressalta que a intervenção pode ocorrer de duas maneiras: em um nível, uma intervenção pode ser qualquer mudança na organização da linha, sendo de natureza estrutural, política ou de procedimentos. Em outro nível, pode ter como resultado final o fato de que uma ou muitas pessoas na organização aprendem algo novo, tendo participação no processo.

Mocsányi (1997) apresenta uma visão otimista do consultor organizacional, relacionando alguns ganhos que podem ser obtidos por aqueles que adotam essa profissão: independência, segurança, auto-sustentabilidade e flexibilidade, ressaltando a flexibilidade como a capacidade de reação aos desequilíbrios da economia por meio da busca de novas alternativas de sobrevivência financeira fora do mercado formal de 
trabalho, que se reduz cada vez mais. Para o autor, as pessoas empregadas possuem uma falsa sensação de segurança, principalmente em função do salário regular, dos benefícios trabalhistas garantidos pela legislação vigente ou concedidos por livre e espontânea vontade pelos empregadores.

Para Block (1991), trabalhar em uma organização significa ser constantemente bombardeado pela pressão de ser esperto e indireto e para ignorar o que sente em um dado momento. O desejo de ser bem-sucedido pode levar o consultor a desempenhar papéis e adotar comportamentos que são alheios a ele. Considera ainda que os consultores são especialmente vulneráveis a esse conflito porque acreditam estar servindo às necessidades dos clientes. Além disso, os projetos tendem a ser de curto prazo, e trabalha-se segundo a vontade do cliente.

Essa sensação de vulnerabilidade pode tornar-se uma racionalização para que os consultores neguem suas próprias necessidades e sentimentos, não sejam autênticos e não expressem sua realidade (BLOCK,1991).

Para Bellman (1993) o consultor deve considerar a consultoria como um meio de vida, como um ideal, uma vocação à qual deve dedicar-se inteiramente, com forte comprometimento e empenho profissional e pessoal. Deve ser como uma religião, com todo amor por si mesmo, pelo trabalho e pelas pessoas. Por outro lado, deve conciliar seu trabalho com sua vida pessoal, tendo claro o quanto quer trabalhar, quais as condições éticas de seu trabalho, recusando os trabalhos para os quais não tenha competência suficiente e dizer não para aqueles trabalhos com resultados dirigidos ou eticamente duvidosos. O autor ressalta também a necessidade de uma forte parceria entre o consultor e seu cliente, por meio do qual, um oferece oportunidades em troca das habilidades e dedicação do outro. Os consultores vão oferecer suas habilidades, especialidades e novas perspectivas para os clientes, devendo mostrar respeito pela organização e pelo que está tentando realizar, bem como respeito pela cultura e valores da organização.

As afirmativas de Bellman (1993), que serão analisadas neste trabalho, mostram que a forma como o consultor encara o próprio trabalho e de como se dá o relacionamento com a empresa-cliente serão decisivos para a qualidade de vida que tem em seu trabalho.

Este estudo, ao adotar os modelos de análise da qualidade de vida e de fontes de pressão no trabalho citados anteriormente, se propôs ao desafio de identificar informações que permitissem conhecer a possível realidade da qualidade de vida e das fontes de pressão que podem estar presentes no trabalho do consultor organizacional.

\section{METODOLOGIA}

\subsection{Problema de pesquisa}

Os consultores atuam na promoção de mudanças organizacionais num contexto de grandes pressões ambientais tais como, altas taxas de desemprego, altas taxas de juros e dificuldade de crédito para as empresas, insegurança e instabilidade de remuneração, concorrência entre os colegas, luta pela sobrevivência, mudança constante de focos de atuação e outras considerações feitas pelos autores citados no capítulo anterior, que apontam para um contexto no qual várias possíveis fontes de pressão podem estar afetando sua qualidade de vida.

Daí surge o problema desta pesquisa que é apresentado da seguinte maneira:

Como é a qualidade de vida do consultor organizacional e quais fontes de pressão estão presentes e podem estar afetando ou não o contexto de seu trabalho? 


\subsection{Objetivos da pesquisa}

O objetivo deste estudo foi analisar a realidade da qualidade de vida e das fontes de pressão no trabalho presentes no contexto de atuação do consultor organizacional externo, buscando identificar as condições que possam estar interferindo no trabalho desse profissional e influenciando seu comportamento dentro e fora do trabalho.

Como objetivos secundários a pesquisa buscou:

- identificar fontes de satisfação e de insatisfação relacionadas ao conteúdo e contexto do trabalho da amostra desses profissionais;

- identificar fontes de pressão presentes no contexto do trabalho desses profissionais;

- identificar fatores ambientais e organizacionais presentes no trabalho do consultor;

- conhecer qual o perfil dos profissionais que atuam na profissão de consultor organizacional, suas principais características pessoais e profissionais;

\subsection{Universo, amostra e grupos pesquisados}

A amostra foi não-probabilística, selecionada pelo critério de acessibilidade (VERGARA, 2000), a partir de: 1. relação de consultores organizacionais credenciados, fornecida pelo Serviço de Apoio à Micro e Pequena Empresa - SEBRAE-MG; 2. pelo Instituto Brasileiro de Consultores Organizacionais - IBCO, que possui sede em São Paulo (SP), mas congrega associados de todo o Brasil, sendo selecionados aqueles residentes em Belo Horizonte (MG); 3. a Lista Telefônica de assinantes comerciais da TELEMAR também em Belo Horizonte (MG).

Participaram da pesquisa um total de 121 consultores organizacionais, pertencente a quatro grupos: um grande grupo, formado por consultores credenciados pelo SEBRAE - MG, consultores estes habilitados para prestar consultoria a pequenas e médias empresas. Outro grande grupo de consultores de empresas listados na lista telefônica de assinantes comerciais da operadora telefônica TELEMAR. Um terceiro e pequeno grupo composto de empresas e profissionais filiados ao IBCO em Belo Horizonte (MG). Um último grupo de consultores foi formado por consultores conhecidos do pesquisador e que se dispuseram a responder pessoalmente ao questionário e se submeter à entrevista.

\subsection{Definição das variáveis do estudo}

Neste estudo, foram investigados cinco grupos de variáveis, extraídas dos modelos propostos por Hackman e Oldham (1975) e Cooper, Sloan e Williams (1988), conforme a figura 2 . 


\begin{tabular}{|l|l|}
\hline \multicolumn{1}{|c|}{ GRUPO DE VARIÁVEIS } & \multicolumn{1}{|c|}{ OPERACIONALIZAÇÃO } \\
\hline 1. Demográficas e ocupacionais & $-\begin{array}{l}\text { Levantamento de dados pessoais, educacionais } \\
\text { e profissionais dos participantes da pesquisa. }\end{array}$ \\
\hline 2. Contexto do trabalho & $\begin{array}{l}\text { Diagnóstico dos sentimentos de satisfação e } \\
\text { insatisfação em relação às possibilidades de } \\
\text { crescimento, segurança, ambiente social, } \\
\text { compensação recebida, supervisão e apoio } \\
\text { recebido da direção das empresas onde atuam. }\end{array}$ \\
\hline 3. Conteúdo do trabalho & $\begin{array}{l}\text { Diagnóstico das dimensões básicas das tarefas } \\
\text { executadas em relação ao inter-relacionamento, } \\
\text { autonomia no trabalho, identidade da tarefa, } \\
\text { habilidades requeridas pelo trabalho, } \\
\text { significação do trabalho, feed-back intrínseco e } \\
\text { extrínseco obtido e a satisfação geral no } \\
\text { trabalho de consultor. }\end{array}$ \\
\hline 4. Ambientais e organizacionais & $\begin{array}{l}\text { Diagnóstico de fatores internos ou externos } \\
\text { ambientais e organizacionais intervenientes no } \\
\text { cotidiano de trabalho dos participantes da } \\
\text { pesquisa. }\end{array}$ \\
\hline 5. Fontes de pressão no trabalho & $\begin{array}{l}\text { Diagnóstico de fontes de pressão } \\
\text { potencialmente presentes no trabalho dos } \\
\text { participantes, sendo fatores ligados } \\
\text { intrinsecamente ao trabalho, ou relacionados do } \\
\text { papel exercido pelos dirigentes das empresas } \\
\text { onde atuam, decorrentes do clima } \\
\text { organizacional ou com interface trabalho/casa } \\
\text { dos participantes. }\end{array}$ \\
\hline
\end{tabular}

Figura 2 - Quadro mostrando as formas de operacionalização dos grupos de variáveis da pesquisa

Fonte: COOPER et al, 1988, e HACKMAN \& ODLHAM, 1975.

Os grupos de variáveis relacionadas ao contexto e conteúdo do trabalho pertencem ao modelo de Hackman e Oldham (1975). As relacionadas às fontes de pressão no trabalho pertencem ao modelo de Cooper, Sloan e Williams (1988). As variáveis ambientais e organizacionais baseiam-se no modelo teórico de Werther e Davis (1983).

As variáveis contidas em cada grupo de variáveis estão citadas no modelo teórico analítico da pesquisa proposto na figura 4 .

\subsection{Instrumentos de coleta de dados}

Tendo em vista a amostragem não-probabilística e a facilidade maior ou menor de acesso aos pesquisados, optamos por utilizar um questionário, adaptado especificamente para esta pesquisa, a partir dos modelos citados, que foi enviado ao endereço eletrônico (e.mail), juntamente com carta de apresentação. Foram também efetuadas entrevistas semi-estruturadas com consultores organizacionais cujo acesso foi possível ao pesquisador.

\subsection{Tratamento dos dados}

Para análise dos dados, foi utilizado o programa estatístico Statistical Package for the Social Science - SPSS - versão 9.0. O motivo da escolha se deve não só ao fato 
de ser um dos mais usados nas pesquisas em Administração, mas também por atender aos objetivos da pesquisa e por ser um programa disponível e utilizado no laboratório do Centro de Pesquisas e Estudos em Administração - CEPEAD - da FACE/UFMG.

A fim de resumir e interpretar o conjunto total de questões, foi utilizada a técnica estatística multivariada de Análise Fatorial.

\section{ANÁLISE E INTERPRETAÇÃO DOS RESULTADOS DA PESQUISA}

\subsection{Análise descritiva das variáveis demográficas e ocupacionais}

\subsubsection{Sexo}

Em relação ao sexo, verifica-se uma grande predominância dos consultores de sexo masculino (76\%) em comparação aos $24 \%$ de sexo feminino, o que nos leva à constatação de que a profissão de consultor organizacional é dominada por profissionais do sexo masculino.

\subsubsection{Faixa etária}

Quanto à idade, nota-se um número significativo de profissionais com mais de $45 \operatorname{anos}(37 \%)$, o que se constitui uma característica, principalmente, dos consultores credenciados pelo SEBRAE-MG, conforme informações obtidas junto à Gerência de RH daquela instituição. O próprio desemprego ocorrido devido aos processos de redução de quadros das empresas também pode ter contribuído para o aumento desse número, haja visto os relatos prestados pelos entrevistados que perderam seus empregos devido à renovação dos quadros ou por opção em planos de incentivo à demissão voluntária ou planos de aposentadoria das empresas.

\subsubsection{Estado civil}

Com relação ao estado civil, a maioria dos consultores é casada (55\%), acrescentando-se que número significativo deles foi casado, estando atualmente separados, divorciados ou desquitados.

Pode-se inferir que essa é uma característica predominante dos consultores organizacionais.

\subsubsection{Filhos}

A maioria dos consultores tem filhos, o que pode ter relação com o fato de a maioria ser casada. Foi relatado nas entrevistas que o fato de ter filhos para criar constitui-se grande fonte de preocupação, devido à inconstância de renda obtida com o trabalho de consultor.

\subsubsection{Faixa etária dos filhos}

Ocorreu um empate amostral com relação à faixa etária dos filhos, sendo que uma metade tem filhos com menos de 18 anos, portanto, possivelmente mais dependentes da renda do trabalho do consultor, enquanto outra metade tem filhos maiores de idade.

\subsubsection{Tempo de formação superior}

Em relação ao tempo de formação superior, um grande número (39\%) tem de quatro a oito anos de formado. $61 \%$ tem mais de nove anos de formação superior, sendo que, desses, $52 \%$ tem mais de 14 anos de formação superior.

Os dados mostram a grande predominância de profissionais mais experientes atuando como consultores, o que demonstra uma característica desse tipo de profissional.

\subsubsection{Tipo de formação superior}

Quanto ao tipo de formação, a amostra foi bastante diversificada, sendo que predominam os formados em administração de empresas, seguidos pelos psicólogos.

Nota-se também um número significativo de engenheiros de diversas especializações, sendo que os principais são os engenheiros agrônomos e os civis. Se 
agrupados todos os tipos de engenheiros, tornaria o grupo de engenheiros o segundo mais freqüente.

Pelas entrevistas realizadas, pode-se hipotetizar que engenheiros estão atuando em áreas de recursos humanos e administrativas.

\subsection{8 Área de atuação}

Em relação à área de atuação, a maioria atua nas áreas de recursos humanos e área administrativa.

\subsubsection{Tempo de atuação como consultor}

Com relação ao tempo de atuação como consultores, nota-se que a maioria tem entre quatro e oito anos que atua na profissão, o que pode estar coincidindo com o período no qual muitas empresas iniciaram processos de enxugamento de suas estruturas organizacionais, levando-os à prestação de serviços.

\subsubsection{Vinculação profissional de trabalho}

Em relação ao tipo de vínculo profissional, a maioria (69\%) dos consultores possui sua própria empresa registrada, o que lhes permite emitir notas fiscais para as empresas em que atuam e por exigência também do SEBRAE-MG, já que muitos são credenciados por essa instituição. $O$ segundo tipo de vinculação profissional mais frequiente foi aquele formado pelos consultores autônomos, que emitem os chamados Recibos de Pagamento de Autônomos - RPAs. O terceiro tipo de vínculo profissional mais freqüente foi aquele formado por consultores que estão associados a alguma empresa de consultoria.

\subsection{A Qualidade de Vida no Trabalho - Conteúdo e contexto do trabalho}

\subsubsection{Variáveis do contexto de trabalho - Sentimentos de satisfação e insatisfação}

Podemos concluir que, de modo geral, aspectos ligados à autonomia que o trabalho possibilita, o desafio representado pelas atividades, o ambiente social onde os trabalhos se desenvolvem e as possibilidades de desenvolvimento e crescimento profissional são aspectos de satisfação no trabalho do consultor. Por outro lado, a segurança propiciada por este tipo de trabalho e a compensação financeira recebida são insatisfatórias. Considerada a média geral, os resultados demonstram que a qualidade de vida no trabalho, relacionada às dimensões do contexto do trabalho, está mais próxima à satisfação do que à insatisfação.

Através da análise dos resultados apresentados nas respostas às questões formuladas, pelos resultados da análise fatorial e pelas afirmações feitas nas entrevistas, foi possível estabelecer uma série de considerações específicas, que serão apresentadas a seguir.

\subsubsection{Satisfação com a Segurança - SS}

Pela análise dos dados percebe-se que o trabalho desempenhado como consultor não possibilita sentimentos mais fortes de segurança ou estabilidade no trabalho o que, de certa forma, parece ser uma característica marcante nesse tipo de trabalho. $O$ sentimento de insatisfação com a segurança que esse tipo de trabalho proporciona parece estar mais relacionado ao presente que ao futuro.

\subsubsection{Satisfação com a Compensação - SC}

Os pagamentos recebidos pelos profissionais encontram-se em níveis satisfatórios, embora estejam mais restritos em termos de quantidade e periodicidade dos recebimentos. Os benefícios concedidos pelas empresas são inexistentes, e a valorização interna dos resultados alcançados não é expressivamente representada nos resultados apresentados nos questionários.

\subsubsection{Satisfação com a Possibilidade de Crescimento - SPC}


Quanto à possibilidade de crescimento profissional, mostram-se resultados em nível elevado, demonstrando um alto grau de satisfação com a possibilidade de crescimento profissional futuro.

\subsubsection{Satisfação com o Ambiente Social - SAS}

Nota-se uma razoável satisfação com o ambiente social e relacionamento interno, devido à oportunidade de conhecer e de ajudar as pessoas que o trabalho de consultor proporciona.

\subsubsection{Satisfação com a Supervisão/direção/cliente - SSU}

De modo geral, percebe-se que os consultores mostram-se satisfeitos com o respeito e o tratamento recebido pelos dirigentes das empresas, com a sua participação nos trabalhos desenvolvidos, com a maneira como as mudanças e inovações são implementadas e com o grau de participação que os consultores têm nas decisões em relação ao próprio trabalho.

\subsubsection{Satisfação com a Autonomia e desafio - AU}

A liberdade de pensamento e ação, o desafio representado pelo trabalho e a independência proporcionada pelo trabalho são aspectos de satisfação dos consultores no trabalho, ressaltando-se que, nas entrevistas semi-estruturadas, essa independência é realçada em relação ao contexto e conteúdo do trabalho executado e não em relação a aspectos financeiros.

\subsubsection{Variáveis do conteúdo e natureza do trabalho - Dimensões básicas da tarefa}

Podemos concluir que, de modo geral, o conteúdo do trabalho caracteriza-se mais marcantemente pela exigência de grande inter-relacionamento, as tarefas inerentes têm grande significância e poder de influência na vida das pessoas, exigem muitas habilidades e permitem boa autonomia.

Considerada a média geral, os resultados demonstram que é boa a qualidade de vida, nos aspectos relacionados ao conteúdo e natureza do trabalho do consultor.

Através da análise dos resultados apresentados nas respostas às questões formuladas, pelos resultados da análise fatorial e considerando as afirmações feitas nas entrevistas, foi possível fazer uma série de afirmações mais específicas, que serão apresentadas a seguir.

\subsubsection{Inter-Relacionamento - IR}

A exigência de que, no exercício do trabalho, haja um relacionamento grande com as pessoas é uma característica bastante marcante evidenciada, com média geral bastante próxima de 4, explicitando a necessidade de o consultor estar em constante relacionamento interpessoal.

Os resultados mostram que os trabalhos dependem de cooperação e grande colaboração das e com as pessoas.

\subsubsection{Autonomia - AU}

Os resultados do questionário mostram que, na média, os consultores têm boa autonomia no desenvolvimento de seus trabalhos. As entrevistas mostram que essa autonomia é principalmente quanto ao como fazer e nem sempre quanto ao o que é permitido fazer.

Os resultados mostram que o tipo de trabalho executado permite uma considerável autonomia e liberdade de definição sobre como executá-lo embora nem tanto quanto ao $o$ que fazer.

\subsubsection{Identidade da Tarefa - IT}

A identidade da tarefa, definida pelo começo, meio e fim representado pelo trabalho desempenhado, encontra-se em média alta, embora, nas entrevistas, perceba-se 
que, muitas vezes, os trabalhos dependem de outras pessoas ou áreas para serem completamente implementados.

\subsubsection{Variedade de Habilidades - VH}

Com resultados acima da média superior, percebe-se que é exigida uma ampla gama de capacidades e de habilidades complexas e de alto nível dos exercentes do trabalho de consultor.

Nas entrevistas, foram ressaltadas habilidades como conhecimento das tarefas, experiência/ competência técnica, experiência prática e bons resultados comprovados, empatia, capacidade de ouvir o cliente, isto é, de entender suas necessidades reais e o que está por trás de suas palavras, sensibilidade, boa base teórico (embora a prática tenha sido mais enfatizada pelos entrevistados), bom relacionamento interpessoal, capacidade de vender idéias e de criar comprometimento nas pessoas em geral, e principalmente, nos dirigentes, discrição, confidencialidade, ética, respeito aos clientes, equilíbrio emocional.

\subsubsection{Significação da Tarefa -ST}

Com média bastante elevada, os resultados expressam a importância que o trabalho representa em termos de seu poder de influenciar a vida e bem-estar das pessoas relacionadas direta e indiretamente ao trabalho desempenhado.

O trabalho é percebido como tendo muita importância e significação, podendo afetar muitas pessoas.

\subsubsection{Feedback Extrínseco - FE}

Com resultados menores em relação aos demais itens, evidenciou-se que é pequeno o feedback recebido dos dirigentes das empresas sobre o modo com que o trabalho dos consultores é conduzido, talvez porque os clientes não se sintam à vontade para opinar sobre a forma como devem ser conduzidos os trabalhos dos consultores.

O feed-back recebido dos clientes, dirigentes, supervisores das empresas em que atuam os respondentes é percebido de forma intermediária entre o nível 2 e 3, mostrando uma divisão de opiniões sobre o tema.

Nas entrevistas, foram citados problemas que eventualmente ocorrem devido à pouca intervenção dos dirigentes na forma como é executado o trabalho do consultor, sendo que a insatisfação dos dirigentes quanto à forma de execução do trabalho nem sempre é explicitada.

\subsubsection{Feedback Intrínseco - FI}

Com relação ao feedback que o próprio trabalho propicia sobre como está se saindo o consultor, percebe-se uma concordância de que o trabalho, por si só, fornece boas indicações sobre o desempenho do profissional.

Os respondentes manifestaram que o próprio trabalho lhes dá parâmetros ou referências de como estão se saindo no mesmo.

Nas entrevistas, isso não ficou tão claro, uma vez que os entrevistados mostraram dúvidas se o trabalho realmente lhes dá certeza de que terão bons resultados. Embora os trabalhos estejam sendo realizados aparentemente bem, isso não significa que alcançaram os objetivos pretendidos pelo cliente ou pelo próprio profissional.

4.2.2.8 Satisfação Geral com o Trabalho - SGT

De um modo geral, os profissionais consultores parecem estar satisfeitos com o trabalho que exercem.

\subsubsection{Variáveis ambientais e organizacionais e sua interferência na dinâmica do trabalho}

Nas questões apresentadas sobre as variáveis citadas, foi solicitado que fossem marcadas as opções baseando-se nas situações que retratassem o dia-a-dia de cada um. 
As opções variaram entre muito satisfatórias, muita influência, muito forte, muito satisfeito, muito integrados, muito entrosados ou muito grande, recebendo quatro pontos, e muito insatisfeitas, nenhuma influência, nenhuma pressão, muito inseguro, muito insatisfeito, sem integração, sem entrosamento e nenhuma resistência recebendo um ponto.

\subsubsection{Condições físicas do ambiente de trabalho}

A média obtida foi de 3,06, evidenciando que as condições físicas de trabalho são consideradas satisfatórias.

\subsubsection{Interferência do ambiente externo - Desemprego na opção como consultor}

A média obtida de 2,2 indica pouca influência do desemprego na opção tomada de atuar como consultores.

Nas entrevistas realizadas os entrevistados tiverem opinião semelhante, embora demonstrassem que acreditam que o desemprego possa ser fator de grande influência na opção de trabalhar como consultores, para aqueles que se encontram atualmente desempregados.

\subsubsection{Interferência do ambiente externo - Concorrência de outros consultores na obtenção de contratos de serviços}

O resultado médio de 2,90 indica que a pressão exercida pela concorrência de outros consultores influencia de maneira significativa na obtenção de novos contratos de prestação de serviços.

Nas entrevistas, foi relatado que o grande número atual de consultores vem tornando mais difícil obter novos trabalhos e fazendo com que sejam apresentadas propostas de preços mais baixos, principalmente para os novos clientes que ainda não conhecem, com maior profundidade, a competência do consultor concorrente. Os valores podem chegar a serem muito baixos de consultores pouco conhecidos, inviabilizando a concorrência na disputa por clientes que dão preferência a preços ou que têm menor experiência com trabalhos de consultoria.

\subsubsection{Segurança no trabalho como consultor}

O resultado médio de 2,48 demonstra sentimento intermediário entre se sentirem seguros ou inseguros no trabalho como consultor organizacional.

Nas entrevistas, os entrevistados se disseram, em sua maioria, seguros em seus trabalhos como consultores, talvez devido à maior experiência como tal (média de nove anos de experiência como consultores).

\subsubsection{Ambiente organizacional - Apoio recebido e relacionamento com o cliente/direção das empresas em que atua}

A média de 3,03 indica que os consultores se disseram satisfeitos com o apoio recebido das direções das empresas em que os consultores atuam.

\subsubsection{Integração/entrosamento com outros profissionais da mesma profissão}

A avaliação foi a mais baixa entre os diversos itens avaliados $(1,84)$, demonstrando a pouca ou muito pouca integração entre os consultores.

Nas entrevistas, os consultores afirmaram que o entrosamento é pequeno, podendo ser maior quando há repasse ou terceirização de parte dos serviços conquistados por alguns para outros colegas. Isso ocorre quando há certos serviços que são conseguidos que não interessam ao consultor executar ou quando o tipo de trabalho não é sua especialidade.

\subsubsection{Ambiente organizacional - Relacionamento interno nos diversos níveis}

hierárquicos da organização

Com os resultados mais altos dentre os itens analisados nesta parte do questionário, o entrosamento interno dos consultores nos diversos níveis hierárquicos das organizações foi considerado entre entrosado e muito entrosamento, com média de 
3,31. Os consultores consideram bom seu relacionamento nos diversos níveis das empresas com os quais necessitam fazer contato.

\subsubsection{Ambiente organizacional - Resistência interna ao trabalho e às mudanças}

Com resultado médio de 2,8, o grau de resistência encontrado pelos consultores parece ser próximo à grande resistência, embora varie entre pequena e grande.

Nas entrevistas, foi afirmado que há desconfiança em relação ao trabalho do consultor, e a resistência normalmente é grande, mas esse grau de resistência depende do envolvimento e comprometimento dos donos e/ou diretores da empresa em implementar as mudanças e quebrar os paradigmas necessários.

\subsection{Fontes de pressão no trabalho - Fatores e fontes \\ 4.3.1 Fatores Intrínsecos ao Trabalho - FIT}

Os resultados da pesquisa mostram que o item que constitui a maior fonte de pressão no trabalho de consultor foi não ter trabalho suficiente para fazer.

Tarefas rotineiras, burocráticas ou monótonas, ter atividades abaixo das próprias capacidades, ter acúmulo de tarefas simples e repetitivas, tarefas e exigências contraditórias ao papel profissional, bem como a busca de alcançar as próprias metas de desempenho no trabalho, ter ausência de liberdade e independência quanto à execução do trabalho também constituem fontes de pressão no trabalho.

Nas entrevistas semi-estruturadas realizadas, foram citados como maiores fontes de pressão a falta de trabalho, ter de ficar perseguindo trabalhos e ter atividades abaixo da capacidade de cada um.

\subsubsection{Papel Gerencial, da direção, do cliente - PG}

Quanto ao papel gerencial exercido pelos donos, diretores ou gerentes das empresas-clientes, o principal item relaciona-se ao apoio ou definições inadequadas dos clientes e à cobrança e implicações dos erros cometidos pelo consultor. Em menor grau, a falta de feedback e de encorajamento por parte dos clientes quanto aos trabalhos também se constitui em fonte de pressão.

Nas entrevistas, foi citada a carência de maior participação dos clientes nos trabalhos, falta de tempo dos mesmos e, eventualmente, conflitos entre o que pensam e o que pensa o consultor.

\subsubsection{Relacionamento Interpessoal - RI}

Quanto ao relacionamento interpessoal, este parece ser o aspecto que menos causa pressão nos consultores. Pode ocorrer uma sensação de isolamento por parte dos consultores.

Nas entrevistas, foi citado como pressão o fato de ter de estar o tempo todo por conta de atender aos clientes, nem sempre sendo remunerado por isso.

\subsubsection{Carreira, Valorização, Realização Profissional - CVRP}

Os itens relacionados aos aspectos acima parecem constituir-se fonte de pressão importante dos consultores.

Perspectivas indefinidas de continuidade dos trabalhos, ter de estar sempre procurando por ele, falta de possibilidades de crescimento profissional, poucas ou inadequadas oportunidades de treinamento e desenvolvimento pessoais são itens citados com freqüência como causadores de pressão estando relacionados à carreira profissional.

Não serem valorizados pelo trabalho que executam, o que recebem diretamente pelo trabalho executado, a falta de outros adicionais na remuneração pelo trabalho, além de os clientes esperarem do consultor resultados além das suas capacidades, são aspectos relativos à valorização profissional que obtiveram pontuação relevante como fontes de pressão no trabalho. 
Nas entrevistas, além dos aspectos acima relacionados, também foi citado por alguns o fato de que alguns empresários acham que os consultores são pessoas desempregadas e sem alternativa de trabalho, como um estigma da profissão.

\subsubsection{Clima e Estrutura Organizacional - CEO}

O clima interno das organizações levando a ameaças de fim de contrato, aliadas aos recursos financeiros insuficientes para trabalhar, é fator gerador de importantes fontes de pressão no trabalho. Em menor grau, a falta de comunicação ou consulta em decisões importantes, a discriminação e favoritismo encobertos também constituem fonte de pressão.

Nas entrevistas, foi dito que, geralmente, os consultores são chamados a trabalhar exatamente quando o clima interno das organizações não é bom.

\subsubsection{Interface Casa - Trabalho - ICT}

A ausência de estabilidade ou segurança na vida familiar, o fato de não conseguir desligar-se do trabalho, mesmo estando em casa, perseguir trabalhos/ contratos à custa da própria vida doméstica também são itens que mereceram avaliações como sendo fontes de pressão no trabalho de consultor.

Nas entrevistas, alguns entrevistados disseram que, muitas vezes, a família fica em segundo plano.

Os itens que tiveram menores pontuações como possíveis fontes de pressão no trabalho e que, portanto, não trazem maiores incômodos aos consultores foram: ter de lidar com novas idéias, técnicas e inovações no trabalho; ter de usar novas tecnologias; conviver com a atitude do cônjuge frente ao trabalho ou carreira do consultor; ter de estar sempre disponível para atender às pessoas; adotar mudanças na maneira de executar o trabalho; conviver com a falta de apoio de outros consultores; lidar com o conflito entre os próprios valores e os da empresa; ter que atuar sem apoio prático por parte das pessoas do próprio convívio profissional, fora do trabalho; ter de trabalhar por muitas horas seguidas ou ter muito pouca ou excesso de variedade no trabalho.

\section{CONCLUSÕES FINAIS}

Para atendermos ao objetivo deste estudo de analisar a realidade da qualidade de vida e das fontes de pressão presentes no contexto da atuação do consultor organizacional, buscamos identificar fontes de satisfação e de insatisfação relacionadas ao conteúdo e contexto do trabalho desses profissionais, bem como identificar as fontes de pressão presentes em seu trabalho. Buscamos também conhecer o perfil dos profissionais que atuam nessa profissão e algumas de suas características pessoais e profissionais.

Com base nos resultados da pesquisa realizada com 121 consultores organizacionais, torna-se possível apresentar inferências e percepções sobre a qualidade de vida e fontes de pressão presentes no dia-a-dia desses profissionais.

Podemos estabelecer um perfil dos profissionais da área, verificando as variáveis demográficas e ocupacionais em que encontramos uma predominância de consultores organizacionais do sexo masculino, com idade acima de 36 anos. Grande parte dos analisados presta serviços ao SEBRAE-MG, que dá preferência aos profissionais mais maduros, muitos deles com mais de 45 anos. Embora mais maduros, quase a metade deles tem relativamente pouco tempo de formado, inferindo-se que possam ter se formado já mais maduros.

A grande maioria dos consultores é formada por pessoas casadas ou ex-casadas e com filhos, o que vem a se constituir uma fonte de insegurança para eles, visto que a 
incerteza dos contratos de trabalho, normalmente temporários, característicos dessa profissão, gera uma descontinuidade, muitas vezes, preocupante para a família.

Profissionais de vários tipos de formação escolar têm desempenhado esse tipo de profissão, embora nesta amostra tenha ocorrido um significativo número de administradores de empresa, com atuação bastante diversificada pela própria característica do curso. Psicólogos e engenheiros de diversas especializações também foram encontrados em número significativo, sendo que as áreas em que mais atuam é a de recursos humanos e administrativa de modo geral.

Os processos de redução de custos das empresas, reestruturações organizacionais das empresas com as chamadas reengenharias, downsizing e processos de terceirização, ocorridos principalmente a partir de meados da década de 1990, parecem ser as razões de que a maioria dos consultores tenha entre quatro e oito anos de atuação como tal, coincidindo com os anos de 1994 e 1999 como o ano de início de suas atividades como consultores organizacionais. Alguns dos entrevistados iniciaram-se como consultores trabalhando para a própria empresa de que eram empregados.

A grande maioria dos consultores tem empresa própria registrada, o que lhes permite emitir notas fiscais para as empresas em que atuam, ter menor custo e descontos de leis sociais em seus rendimentos e satisfazer seu desejo de se tornarem donos de suas próprias empresas, com maior liberdade para administrarem a própria vida, conforme também afirmado pelos consultores entrevistados.

De acordo com o modelo das características da tarefa de Hackman e Oldham (1975), verificamos diferentes resultados para as variáveis relacionadas à qualidade de vida no trabalho, sejam elas de contexto ou de conteúdo do trabalho.

Os sentimentos de satisfação ou de insatisfação em relação ao trabalho como consultor, manifestados na pesquisa, mostraram que esse tipo de trabalho não possibilita a sensação de estabilidade ou de segurança, especialmente quanto à continuidade da prestação de serviços aos clientes atuais. Os consultores acreditam que, no futuro, quando sua experiência se consolidar e/ou o momento atual de instabilidade e recessão por que passa o país no momento diminuir, aí sim poderão se sentir mais seguros e mais estabilizados na profissão que escolheram.

A compensação recebida expressa pelos valores pagos pelos clientes pelos serviços profissionais prestados, é percebida como satisfatória embora não tenha qualquer tipo de benefício marginal, como seguro-saúde, seguro de vida, alimentação, $13^{\circ}$. Salário, bônus, participação nos lucros e outros benefícios comuns aos empregados das empresas. Qualquer tipo de adicional deve ser pago pelo próprio profissional. A valorização pelos bons trabalhos realizados pelo consultor será expressa pela maior possibilidade de continuidade da prestação de serviços e indicações para outros trabalhos e empresas-clientes.

Os consultores mostraram um alto nível de satisfação com o que o trabalho representa em termos de crescimento e enriquecimento profissionais, pois adquirem uma visão mais diversificada e vivem situações em diferentes contextos e realidades empresariais.

A oportunidade de ajudar e conhecer pessoas nesse tipo de trabalho, bem como o tratamento respeitoso recebido dos dirigentes das empresas, é satisfatória, embora não forneçam muito feedback direto com relação à qualidade do trabalho desenvolvido pelos consultores.

Um aspecto muito valorizado nos questionários e ressaltado nas entrevistas relaciona-se à autonomia e desafio que este trabalho representa, permitindo ao profissional decidir principalmente, o como fazer o trabalho, sendo que o o que deve ser feito, muitas vezes, permanece controlado pelo dirigente. A autonomia também não se 
manifesta com relação aos aspectos financeiros, que continuam sendo controlados pelas empresas-clientes.

Embora o trabalho do consultor, freqüentemente, dependa de outras pessoas ou áreas para ser completamente implementado, há uma boa identidade da tarefa, representada pelo começo, meio e fim dos trabalhos realizados.

Percebe-se que o trabalho do consultor pressupõe o exercício de uma variedade grande de habilidades e capacidades requeridas. Os altos resultados apresentados nos questionários foram complementados pelos entrevistados, que destacaram uma série de habilidades e características necessárias para um bom profissional da área como experiência no tipo de trabalho que se propõe a realizar, com reconhecida competência prática principalmente e teórica, boa capacidade de empatia e de ouvir o cliente, percebendo suas necessidades e desejos, bom relacionamento interpessoal, discrição, respeito aos clientes, equilíbrio emocional, capacidade de vender idéias e de criar comprometimento nas pessoas em geral envolvidas no trabalho e, sobretudo, nos dirigentes das empresas em que atuam.

A satisfação com a significação da tarefa expressa a importância que o trabalho dos consultores representa em relação à sua capacidade de influenciar a vida e o bemestar das pessoas relacionadas ao trabalho que executam, sendo outro fator gratificante para esses profissionais. Embora, geralmente, os dirigentes das empresas não expressem diretamente sua satisfação com os resultados dos trabalhos realizados, o próprio trabalho do consultor costuma ser seu parâmetro de feedback sobre a qualidade do trabalho que está prestando.

De um modo geral, os consultores mostram-se satisfeitos com o trabalho que executam, demonstrando que é satisfatória a qualidade de vida no trabalho relacionada às variáveis de conteúdo e contexto do trabalho propostas por Hackman e Oldham (1975).

Ao procedermos à análise dos fatores ambientais e organizacionais, inspirados no referencial teórico estabelecido por Werther e Davis (1983), verificando como diversos fatores são intervenientes no cotidiano de trabalho dos consultores pôde-se chegar a algumas conclusões.

Com relação a aspectos internos no ambiente de trabalho dos consultores, as condições físicas onde estes normalmente trabalham são boas, assim como são satisfatórios o apoio recebido e o relacionamento com o cliente e direção das empresas em que atuam. Embora este apoio se manifeste, foi evidenciada nos resultados uma grande resistência interna aos trabalhos exercidos pelos consultores nas organizações, embora estes tenham um bom trânsito e relacionamento com os diversos níveis das empresas em que atuam.

Com relação a fatores ambientais externos, embora acreditássemos que o fator desemprego atual pudesse estar influenciando na opção do consultor de atuar como tal, isso não se confirmou. Os resultados indicaram pouca influência do desemprego como impulsionador da entrada de muitos profissionais no mercado de consultoria. Também nas entrevistas realizadas, embora alguns entrevistados manifestassem sua crença de que o desemprego pudesse estar influenciando, esta não foi uma opinião marcante.

Pelos resultados apresentados pode-se concluir também ser forte a pressão exercida pela concorrência entre os consultores na obtenção de novos contratos de prestação de serviço. Esse aspecto foi evidenciado também nas entrevistas em que foi dito que o grande número de consultores atualmente no mercado vem tornando mais difícil a obtenção de novos contratos e forçando a queda de preços, até patamares, muitas vezes, inaceitáveis para aqueles há mais tempo estabelecidos no mercado. O 
cliente quase sempre prioriza o preço, em detrimento da possível má qualidade dos serviços prestados por profissionais inexperientes.

Outro aspecto importante relaciona-se ao entrosamento entre os profissionais da área. Houve uma marcante evidência de que não há entrosamento entre os diversos profissionais da área ou, se ocorre, é pequeno ou limita-se ao repasse de trabalhos que não são de interesse ou competência de um consultor. $O$ desentrosamento parece se acentuar pela inexistência de um órgão ou instituição que abrigue e seja centro de referência para esses profissionais em Minas Gerais. Embora exista um sindicato que se intitule representante dos consultores organizacionais (SESCON-MG), sabe-se que este sindicato surgiu para servir aos interesses dos contabilistas e contadores, ampliando, posteriormente, sua base pela ausência de representantes dos consultores organizacionais. Há, apenas em São Paulo, um Instituto que procura congregar, disciplinar e orientar os profissionais de consultoria organizacional, denominado Instituto Brasileiro de Consultores Organizacionais - IBCO.

Analisando-se as fontes de pressão presentes no trabalho do consultor organizacional, inspirados no modelo teórico proposto por Cooper, Sloan \& Williams (1988), pudemos concluir que vários são os aspectos que se constituem em fonte de pressão no trabalho dos consultores e que podem estar afetando sua qualidade de vida.

Quanto aos fatores intrínsecos ao trabalho, o exercício de tarefas rotineiras ou repetitivas é um fator que incomoda aos consultores, principalmente, ao considerarmos que, conforme citado anteriormente, a variedade de habilidades requerida para o normal exercício dessa profissão é grande. Ao ter que executar tarefas repetitivas, rotineiras o trabalho se torna monótono e pouco motivador, assim como se não houver liberdade e autonomia no trabalho.

Ainda intrínseco ao trabalho, o fato de ter que estar normalmente preocupado com o fim de um trabalho e em busca de outros novos, é um fator que causa muita preocupação e é uma grande fonte de pressão no trabalho do consultor, exceção feita àqueles que estão ligados diretamente a alguma empresa de consultoria grande, com contratos de exclusividade a ela.

Embora ocorra uma sensação de isolamento dos consultores, pode ocorrer uma falta de privacidade na vida dos consultores quanto são procurados a qualquer hora para prestar algum tipo de informação fora do horário normal de trabalho das empresas, sem serem remunerados a mais por tal.

Com relação à valorização profissional, é comum a sensação de não valorização adequada pelo trabalho realizado, ou pela falta de outros adicionais, ou por expectativas profissionais inadequadas à capacidade de cada um. Uma agravante citada nas entrevistas se relaciona ao fato de alguns empresários considerarem o consultor como alguém desempregado que, por falta de opção, atua como tal, sendo este um possível estigma dessa profissão.

O clima interno das organizações, suas dificuldades financeiras insuficientes para promover as mudanças necessárias nas organizações, levando a ameaças de suspensão ou redução dos trabalhos de consultoria foram importantes aspectos presentes nos resultados dos questionários e citados com ênfase nas entrevistas. Acrescente-se a isso o fato de os consultores trabalharem nas empresas justamente quando estas querem melhorar algum aspecto importante e quando o clima interno geralmente está ruim.

Complementando, a necessidade constante de estar em busca de trabalho, a ausência de estabilidade ou segurança financeiras, o fato de não conseguir se desligar do trabalho, mesmo estando em casa, são fontes de pressão que podem fazer com que consultores coloquem a família em segundo plano e trazer prejuízos às relações familiares, comprometendo a qualidade de vida no trabalho do consultor organizacional. 
As conclusões aqui colocadas obviamente não esgotam o estudo da qualidade de vida e fontes de pressão no trabalho do consultor organizacional, sendo apenas um início de pesquisas sobre o tema.

Cabem ainda algumas recomendações sendo que, do ponto de vista acadêmico e tendo em vista os resultados desta pesquisa, podemos sugerir:

- que futuras pesquisas sejam feitas em outros estados, por exemplo, em São Paulo, onde os consultores organizacionais parecem estar melhor organizados em associações e onde parece haver maior volume de trabalho na área do que no Estado de Minas Gerais e podem estar presentes outras características nos dirigentes empresariais e nos consultores organizacionais;

- que, em termos metodológicos, considerando a riqueza dos dados obtidos por meio das entrevistas semi-estruturadas que possibilitaram a melhor compreensão das variáveis investigadas, os futuros estudos de qualidade de vida no trabalho que venham a ser realizados incluam abordagens qualitativas, tanto no sentido de descrever as variáveis pesquisadas, quanto de validar os resultados obtidos mediante a aplicação de métodos quantitativos;

- que o pesquisador procure também mesclar os instrumentos de coleta de dados validados pela academia com alguns de criação própria.

\section{REFERÊNCIAS BIBLIOGRÁFICAS}

. ALBRECHT, K. O gerente e o estresse - faça o estresse trabalhar para você. Rio de Janeiro: Zahar, 1988.

. ARROBA, T.; JAMES, K. Pressão no trabalho: stress - um guia de sobrevivência. São Paulo: McGraw-Hill, 1988.

. AUBERT, N. A neurose profissional. Revista de Administração de Empresas, São Paulo, v. 33, n.1, p. 84-105, jan./fev. 1993.

. BELLMAN, G. A vocação do consultor. São Paulo: Makron Books, 1993.

. BLOCK, P. Consultoria: o desafio da liberdade. São Paulo: Makron Books, 1991.

- BRASIL. Ministério do Trabalho. Emprego no Brasil: Diagnóstico e Políticas. Disponível em www.mtb.gov.br/public/emprego.

. BRETAS PEREIRA, M.J.L. Na cova dos leões. O consultor como facilitador do processo decisório empresarial. São Paulo: Makron Books, 1999.

. COOPER, C.L.; SLOAN, S.J.; WILLIAMS, J. Occupational stress indicator management guide. Windsor: NFER -Nelson, 1988.

. COUTO, H. Stress e qualidade de vida dos executivos. Rio de Janeiro: COP, 1987.

. EVANS, P. Carreira, sucesso e qualidade de vida. Revista de Administração de

Empresas, São Paulo, v. 36, n.3, p. 14-22, Jul./Ago./Set. 1996.

. GODOY, A.S. Pesquisa qualitativa e sua utilização em administração de empresas.

Revista de Administração de Empresas, São Paulo: v.35, n.4, p.65-71, jul./ago. 1995 b.

- GREENBAUM, T.L. Manual do consultor: guia completo para a prática da consultoria. Rio de Janeiro: LTC, 1991.

. HACKMAN, J.R.; OLDHAM, G.R. Development of the job diagnostic survey. Journal of Aplied Psychology. Santa Monica:v.60,n.2, p.159-170, 1975.

. HERZBERG, F. One more time: how do you motivate employees? Harvard Business Review, Boston, v.46, n.1, p. 24, jan./fev. 1968.

. KILIMNIK, Z.M.; RODRIGUES, S.B. Trajetórias, transições e âncoras de carreira: um estudo comparativo e longitudinal com profissionais de recursos humanos. O\&S. Salvador: v. 7, n. 17, Jan./Abr. 2000. 
. KILIMNIK, Z.M.; CASTILHO, I.V. Trajetórias e transições de carreira: um estudo longitudinal sobre a qualidade de vida de profissionais assalariados de recursos humanos que experimentaram a passagem para o trabalho autônomo. Trabalho aceito para apresentação e publicação nos anais do ENANPAD 2002.

. KUBR. M. Consultoria: um guia para a profissão. Rio de Janeiro: Guanabara, 1986.

. MASLOW A. H. Motivation and personality. New York: Harper \& Row, 1954.

- MELO, M.C.O.L. Carreira gerencial: os dramas e as tramas de gerentes em organizações brasileiras. O\&S, Salvador, v.7, n. 17, p.125, Jan./abr. 2000.

. MOCSÁNYI, D.C. Consultoria: o que fazer, como vender. São Paulo: Gente, 1997.

. MORAES, L.F.R. Características pessoais e de qualidade de vida no trabalho como antecedentes do comprometimento e stress organizacional: um estudo de profissões desgastantes e de risco. Belo Horizonte: CEPEAD/FACE/UFMG, 1994. (Projeto de pesquisa).

. MORAES, L.F.R; KILIMNIK, Z.M. Comprometimento organizacional, qualidade de vida e stress no trabalho: uma abordagem de diagnóstico comparativo. Belo Horizonte: CEPEAD/FACE/UFMG, 1994. (Relatório de Pesquisa).

. MORAES, L.F.R.; KILIMNIK, Z.M., RAMOS, W.M. O atual estado da arte da qualidade de vida no Brasil. In: ENCONTRO NACIONAL DA ANPAD, 18, Anais...Curitiba: ANPAD, 1994.

et al. Resgatar a qualidade de vida no trabalho: uma imposição atual. Revista Tendências no Trabalho. São Paulo: abr. 1989.

. MORAES, L. R. F.; SWAN, J. A.; COOPER, C. L. A study of occupational stress among government collar workers in Brazil using the occupational stress indicator. Stress Medicine, v.9, p. 91-104, John Wiley \& Sons, 1993.

. OLIVEIRA, D.P.R. Manual de consultoria empresarial: conceitos, metodologias, práticas. São Paulo: Atlas, 1999.

- QUINTELLA, H.M. Manual de psicologia organizacional da consultoria vencedora. São Paulo: Makron Books, 1994.

. SCHEIN, E.H. Consultoria de procedimentos: seu papel no desenvolvimento organizacional. São Paulo: Edgar Blücher, 1972.

. TELELISTA. Lista telefônica comercial de Belo Horizonte da TELEMAR . Rio de Janeiro: Telelistas (Região 1), 2002.

. TRIST, E.L. The socio-technical perspective: the evolution of socio-technical systems as a conceptual framework and as action research program. In: VAN DE VEM.:

. VEIGA, A. Tempos Modernos. Veja, São Paulo, ed.1643, ano 33, n.34, p.122-9, 2000.

. VIEIRA, A. A qualidade de vida no trabalho e o controle da qualidade total. Florianopolis: Insular, 1996.

. WALTON, R. Quality of work life: what is it? Sloan Management Review, v.15, n.1, p.11-21, Dec.1973.

. WEINBERG, G.M. Consultoria- o segredo do sucesso. São Paulo: Ed. McGraw-Hill, 1990.

. WERTHER, B.W.J.; DAVIS, K. Personnel management and human resources. New York: Mc Graw Hill, 1983.

. WOOD, T. Mudança organizacional e transformação da função de recursos humanos. In: WOOD, T. (Org,) Mudança organizacional: aprofundando temas atuais em administração de empresas. São Paulo: Atlas, 1985. 